\title{
Utilisation of recycled thermoplastics sourced from rejected-unused disposable diapers as polymer blends
}

\author{
M.J. Taufiq ${ }^{1}$, Z. Mustafa ${ }^{2 *}$ and M.R. Mansor ${ }^{1}$ \\ ${ }^{1}$ Faculty of Mechanical Engineering, Universiti Teknikal Malaysia Melaka, 76100 \\ Durian Tunggal, Melaka, Malaysia \\ ${ }^{2}$ Advanced Manufacturing Centre, Faculty of Manufacturing Engineering, Universiti \\ Teknikal Malaysia Melaka, 76100 Durian Tunggal, Melaka, Malaysia \\ *Email: zaleha@utem.edu.my \\ Phone: +6063316533; Fax: +6063316411
}

\begin{abstract}
The blending of two or more thermoplastics could produce polymer blends, which are preferable compared to developing a new type of plastic. This paper presents the study on the utilisation of recycled thermoplastic polymers which are recovered from rejectedunused disposable diapers. The aim of study is to characterise the effect of manufacturing temperature on the tensile and morphological properties of recycled plastic blend. Besides that, the polymer blend sourced from virgin materials was also prepared to compare the properties. The recycled and virgin materials were blended by using an internal mixer with fixed parameters. Later, the blended materials were crushed and moulded using hot compression moulding with temperature variations of $180{ }^{\circ} \mathrm{C}, 190{ }^{\circ} \mathrm{C}$ and $200{ }^{\circ} \mathrm{C}$. The tensile tests were conducted in accordance with the ASTM D638 using a universal testing machine, followed by scanning electron morphological analysis. The results showed that as temperature increases, tensile strength decreases and tensile strain increases for both recycle and virgin blends. Tensile strength and strain for the recycled blend were also lower than the virgin blend at all temperatures, due to low miscibility in the recycled blend compared to the virgin one. The low miscibility caused more macrophase separation and resulted in poor adhesion between the polymer components. Also, the increase of temperature caused the tensile modulus to be reduced for the recycled blend. Meanwhile for the virgin blend, the modulus reduced at $190^{\circ} \mathrm{C}$ but increased suddenly at temperature of $200{ }^{\circ} \mathrm{C}$.
\end{abstract}

Keywords: Polypropylene/polyethylene blends; recycle; compression moulding; tensile properties; morphological properties.

\section{INTRODUCTION}

The push towards environmental sustainability especially on harnessing the benefits offered by recycled plastics at their end-of-life stage has received attention from various researchers. Recycled plastics are viable low cost alternative materials to many applications. Moreover, plastic recycling process also reduces the cost to separate the waste in the landfill [1]. The recycling of plastic waste sourced from industrial activities could also support the energy, environment and sustainable development, as well as provide additional economic benefits such as employment and additional income [2]. As a modern and developing country, Malaysia has taken part in preserving the environment 
by promoting the National Recycling Programme in the 8th Malaysia Plan (MP) for 20012005 [3]. Within the government plan, it is stated that among the objectives of the programme is to minimise the volumes of waste disposal by landfills.

On the other hand, industrial waste is also one of the main contributors for plastics, which have the potential to be used as recycled plastics. One of the untapped potentials is plastic waste derived from RUDD during the production of a product, and in its normal form it primarily contains plastics (polypropylene, polyethylene and polystyrene), cellulose pulp and super absorbent polymer [4]. The average weight of a clean disposable diaper is approximately $41 \mathrm{~g}$, and plastic elements comprise up to $23 \%$ of the overall diaper material composition[5]. The diapers industry runs on high volume of production to support growing customer demand. Based on the statistics by Pampers ${ }^{\circledR}$ on habits and practices by diapers consumers in 2007 , it was reported that the average number of diapers used per children was 4,623 diapers for USA and Canada, while the average number of diapers used per children was 3,796 diapers for the European region [6]. To date, the RUDD, treated as industrial wastes in diapers production are disposed of in landfills. Considering the amount of plastics (polypropylene and polyethylene) which can be recovered from the rejected product, the potential of utilising the plastics components for other applications is very high through the use of mechanical separation process. However, the actual application of recycled plastics recovered from RUDD is still lacking due to very limited information on the material performance, especially on the mechanical properties of the plastic blends. In this project, the authors would like to present the experimental study on developing the thermoplastic blends sourced from the RUDD which consist of polypropylene (PP) and polyethylene (PE) in order to turn waste into value. The aim of this study is to characterise the effect of manufacturing temperature on the tensile and morphological properties of the recycled PP/PE blend (r-PP/PE). In addition, the study also involves comparison on the properties of the virgin PP/PE blend (v-PP/PE) with r-PP/PE. Morphological examination was done on the fracture samples.

\section{METHODS AND MATERIALS}

\section{Materials}

The RUDD were supplied by ZFH Industries Sdn. Bhd. (Klang, Malaysia) in shredded form. The absorbent gel and plastic components containing PP/PE (70/30 wt.\%) were separated. The commercial virgin PP and LLDPE were used for comparison with $\mathrm{r}$ PP/PE. The PP (with a density of $1.48 \mathrm{~g} / \mathrm{cm}^{3}$ ) and LLDPE (with gravity of $0.9 \mathrm{~g} / \mathrm{cm}^{3}$ ) were respectively supplied by Lotte Chemical Titan and Polyethylene Malaysia Sdn. Bhd.

\section{Sample Preparation}

The PP/PE blend was compounded using an internal mixer machine (HAAKE Rheomix Lab Mixer) for mixing temperature of $180^{\circ} \mathrm{C}$, mixing time of 10 minutes and rotor speed of $50 \mathrm{rpm} .50 \mathrm{~g}$ of sample were used for each compounding procedure. Meanwhile, 70 wt.\% of PP (35 g) and $30 \mathrm{wt} . \%$ of PE (15 g) were used for v-PP/PE blend production. The r-PP/PE and v-PP/PE blends were crushed using a crusher machine and compressmoulded via a laboratory hot compression moulding machine (Go Tech). The samples were placed inside a window-framed stainless steel mould with dimensions of $200 \mathrm{~mm}$ wide x $200 \mathrm{~mm}$ long x $3 \mathrm{~mm}$ thick. Three variations of temperature were used during compression moulding which were $180{ }^{\circ} \mathrm{C}, 190{ }^{\circ} \mathrm{C}$ and $200{ }^{\circ} \mathrm{C}$. The samples were kept at zero pressure for 15 minutes of pre-heating. Later, the samples were compacted at a 
pressure of 20 tons for 15 minutes followed by cooling under the same pressure. The final products were in panel shapes.

\section{Tensile Test}

Tensile tests were performed in accordance with ASTM D638 standard [7] using a universal testing machine (Instron, UK). The tensile test specimen was prepared from the PP/PE panel that was machined cut into a dumbbell shape with dimensions of $20 \mathrm{~mm}$ wide $x 165 \mathrm{~mm}$ long and the width of the narrow section was $13 \mathrm{~mm}$. The application of an extensometer with $25 \mathrm{~mm}$ of gauge length was used for elongation detection. The tests were carried out at $2 \mathrm{~mm} / \mathrm{min}$ of crosshead speed.

\section{Scanning Electron Microscopy}

The morphology of both r-PP/PE and v-PP/PE blends was analysed using scanning electron microscope (SEM) (JEOL, USA) at 200x magnification. The tensile fractured surfaces of $\mathrm{r}-\mathrm{PP} / \mathrm{PE}$ and $\mathrm{v}-\mathrm{PP} / \mathrm{PE}$ samples were examined to assess the failure mechanisms. A mini coater sputter machine was used to coat the SEM samples before the observation.

\section{RESULTS AND DISCUSSION}

Table 1 and 2 present the effect of the compression temperature onto the tensile properties of r-PP/PE and v-PP/PE samples, respectively. It can be observed that the mechanical properties of the blends are influenced by their compression temperature [2]. Figure 1 illustrates the strain-stress curve of both r-PP/PE and v-PP/PE which revealed a semiductile characteristic [8]. The semi-ductile characteristic was obtained since the blend consisted of PP and PE, which have brittle and ductile properties, respectively. The semiductile region can be observed from the tensile fracture surface of v-PP/PE, shown by the SEM image in Figure 2. From the image, the lower and upper regions emphasised the ductile and brittle characteristics, respectively.

Table 1. Summary of tensile properties of r-PP/PE.

\begin{tabular}{cccc}
\hline $\begin{array}{c}\text { Compression moulding } \\
\text { temperature }\left({ }^{\circ} \mathrm{C}\right)\end{array}$ & $\begin{array}{c}\text { Max strength } \\
(\mathrm{MPa})\end{array}$ & $\begin{array}{c}\text { Tensile modulus } \\
(\mathrm{MPa})\end{array}$ & $\begin{array}{c}\text { Strain at max } \\
\text { load }(\%)\end{array}$ \\
\hline 180 & $9.36 \pm 0.59$ & $285 \pm 8$ & $3.29 \pm 0.12$ \\
190 & $8.58 \pm 0.57$ & $249 \pm 11$ & $3.44 \pm 0.19$ \\
200 & $8.31 \pm 0.39$ & $217 \pm 15$ & $17.18 \pm 2.73$ \\
\hline
\end{tabular}

Table 2. Summary of tensile properties v-PP/PE.

\begin{tabular}{cccc}
\hline $\begin{array}{c}\text { Compression moulding } \\
\text { temperature }\left({ }^{\circ} \mathrm{C}\right)\end{array}$ & $\begin{array}{c}\text { Max strength } \\
(\mathrm{MPa})\end{array}$ & $\begin{array}{c}\text { Tensile modulus } \\
(\mathrm{MPa})\end{array}$ & $\begin{array}{c}\text { Strain at max } \\
\text { load }(\%)\end{array}$ \\
\hline 180 & $21.97 \pm 2.81$ & $282 \pm 42$ & $7.83 \pm 0.40$ \\
190 & $19.64 \pm 2.27$ & $243 \pm 33$ & $8.16 \pm 1.07$ \\
200 & $17.30 \pm 1.42$ & $353 \pm 21$ & $13.48 \pm 2.59$ \\
\hline
\end{tabular}




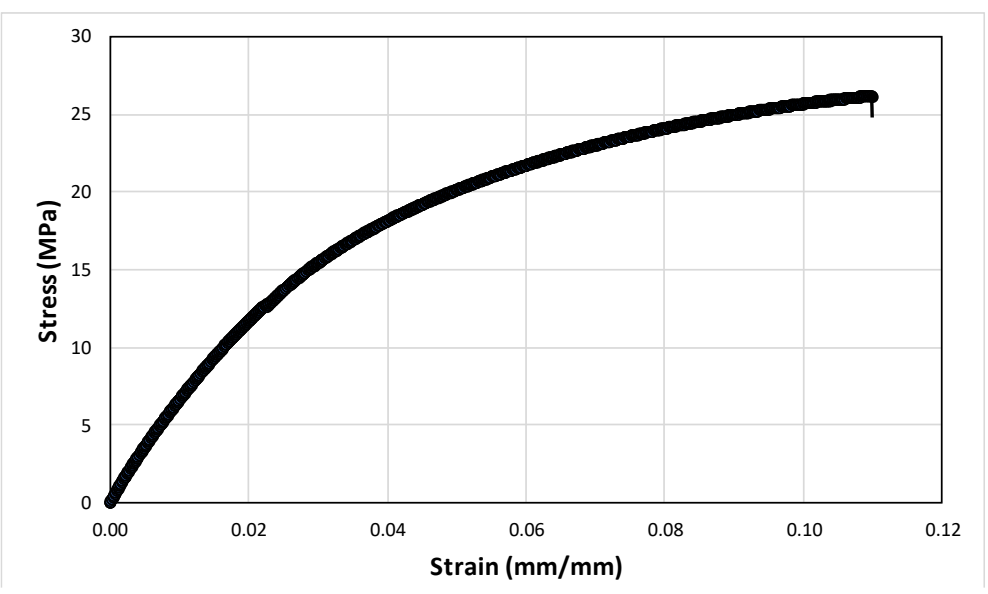

Figure 1. Typical strain-stress curve of tensile test on PP/PE blend.

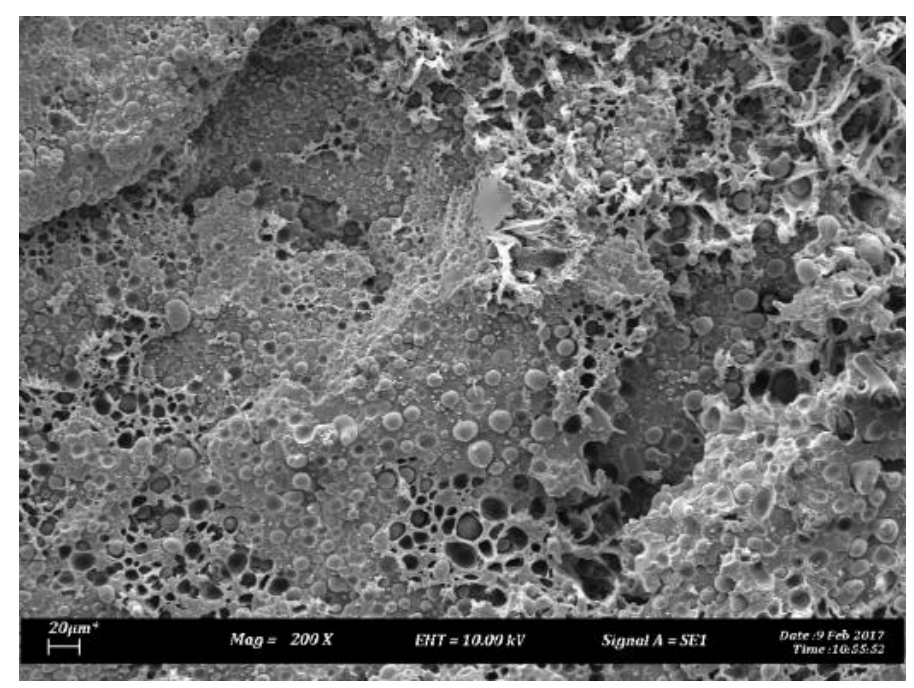

Figure 2. SEM image of v-PP/PE showing semi-ductile phase at $180{ }^{\circ} \mathrm{C}$.

Figure 3 presents the effect of temperature on the mechanical properties of the composite. It can be observed that the tensile strength of r-PP/PE reduced from $9.36 \mathrm{MPa}$ to $8.31 \mathrm{MPa}$ from when the moulding temperature increased from $180{ }^{\circ} \mathrm{C}$ to $200{ }^{\circ} \mathrm{C}$. A similar trend can also be observed in the virgin matrix. Besides that, the tensile strength also decreased when the temperature increased from $180{ }^{\circ} \mathrm{C}$ to $200^{\circ} \mathrm{C}$. These behaviours showed that higher temperature caused degradation in polymer chains which led to weak bonding strength between the chains. A similar result was reported by Strapasson et al. [2], where in PP/PE blend with PP rich compound (75 wt.\%), the maximum tensile strength was obtained at processing temperature of $180^{\circ} \mathrm{C}$ as compared to higher processing temperatures of $190{ }^{\circ} \mathrm{C}$ and $200{ }^{\circ} \mathrm{C}$. Figure 3(b) shows the tensile modulus of $\mathrm{r}-\mathrm{PP} / \mathrm{PE}$ at $180{ }^{\circ} \mathrm{C}$, which decreased from $285 \mathrm{MPa}$ to $226 \mathrm{MPa}$ when the temperature reached $200{ }^{\circ} \mathrm{C}$. However, the tensile modulus of v-PP/PE was at the highest when the temperature used was $200{ }^{\circ} \mathrm{C}$, indicating v-PP/PE became stiffer at higher temperature. Figure 4 shows the strain at maximum load for $\mathrm{r}-\mathrm{PP} / \mathrm{PE}$ and $\mathrm{v}-\mathrm{PP} / \mathrm{PE}$, which revealed that the strain increased from $3.29 \%$ to $17.18 \%$ when the temperature increased from $180{ }^{\circ} \mathrm{C}$ to $200{ }^{\circ} \mathrm{C}$. A similar behaviour was also found in $\mathrm{v}-\mathrm{PP} / \mathrm{PE}$, where the strain at maximum load increased from $7.83 \%$ to $13.48 \%$. The improvement of tensile strain indicates a better 
homogeneity at a higher temperature, which can be observed from the SEM images as shown in Figure 5. Less phase separation was also found on the PP/PE blend sample moulded at $200{ }^{\circ} \mathrm{C}$ as compared to $180^{\circ} \mathrm{C}$.

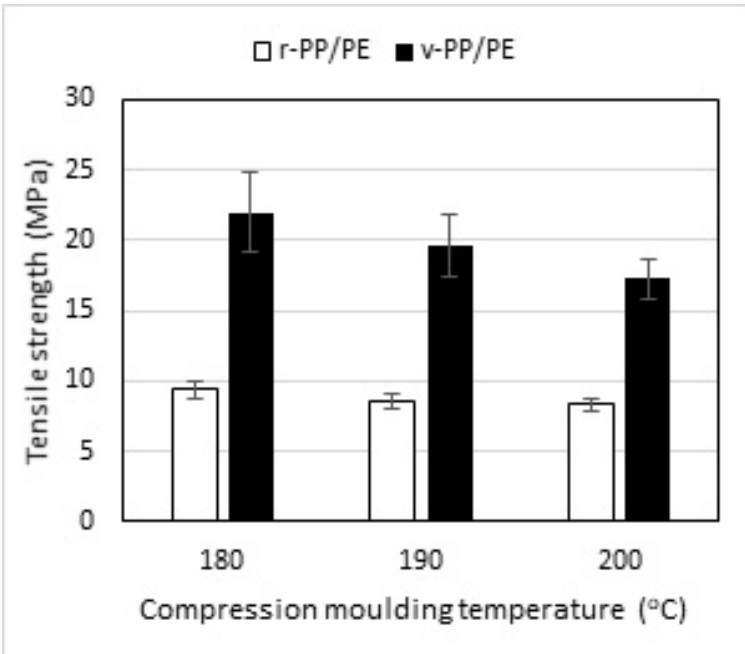

(a)

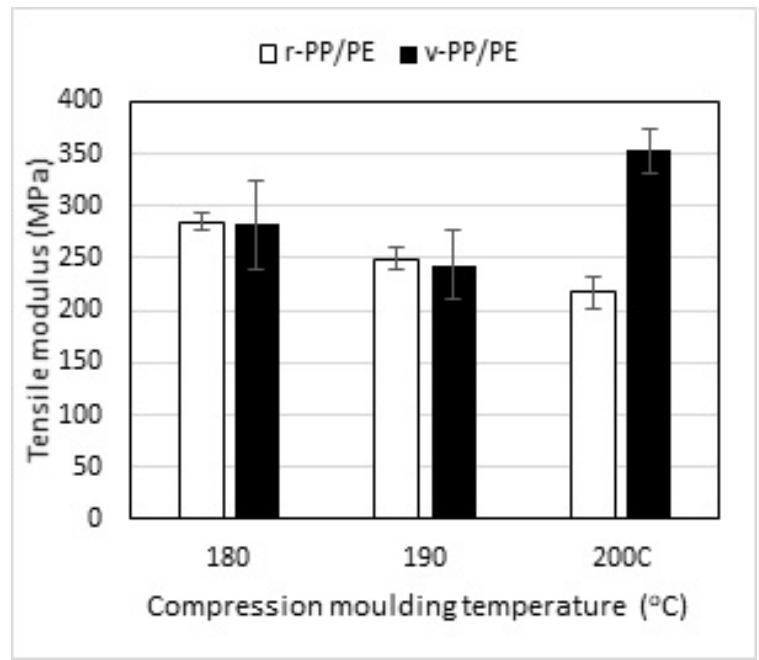

(b)

Figure 3. Tensile properties of r-PP/PE and v-PP/PE blends at varying compression moulding temperatures; (a) Strength, (b) Modulus.

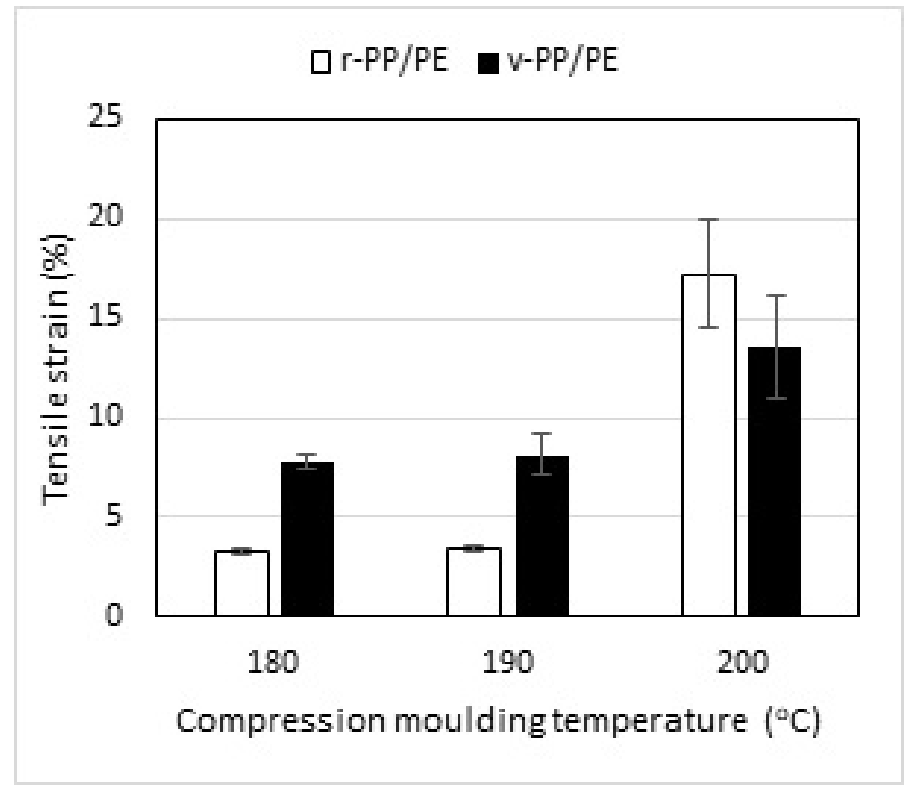

Figure 4. Comparison of tensile strain of r-PP/PE and v-PP/PE blends at varying compression moulding temperatures.

Figure 6 shows the SEM images taken from the tensile fracture surface of r-PP/PE and $\mathrm{v}-\mathrm{PP} / \mathrm{PE}$, respectively. The $\mathrm{r}$-PP/PE showed less miscibility between PP and PE inside the blend during melting compared to the v-PP/PE blend, which was more miscible. The less miscibility caused the lower tensile strength of r-PP/PE compared to v-PP/PE, and more macrophase separation within the r-PP/PE blend. This macrophase separation led to poor adhesion between phases, thus, affecting the final properties of the r-PP/PE blend [9]. Furthermore, the morphological properties influenced the inter-crystalline links 
between lamellae and interactions between the two incompatible phases and their mutual boundaries [10]. The differences in tensile strength and modulus between r-PP/PE and v$\mathrm{PP} / \mathrm{PE}$ were also caused by impurities found in r-PP/PE which increased the phase separation and reduced the stress transfer between PP and PE inside the blend [11]. Morphological analysis in Figure 6(a) highlights the existence of impurities in the form of fibre-like element which originated from actual recycled disposable diapers. This was possibly due to the plastic separation process of the disposable diapers which was insufficient to segregate the plastic material from other diaper components.

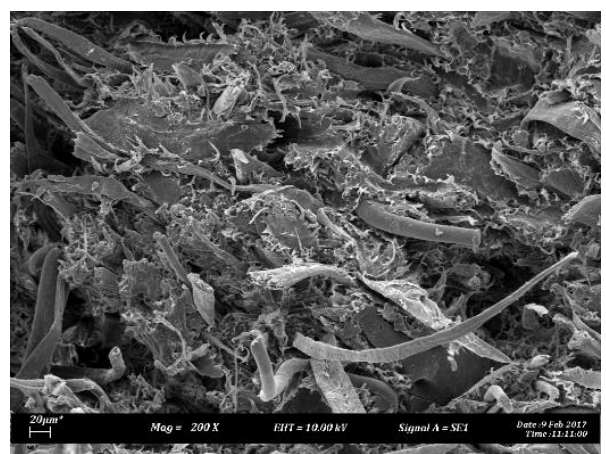

(a)

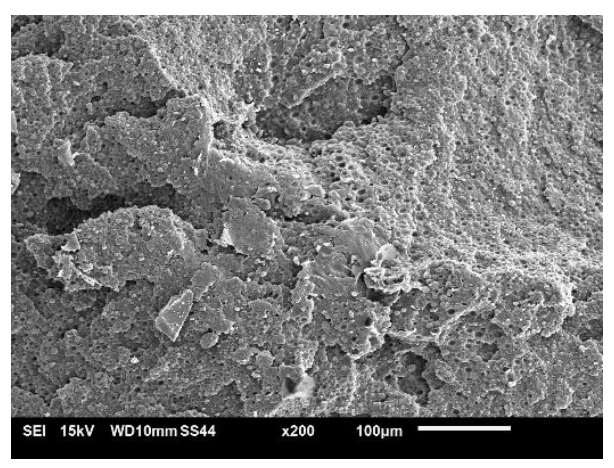

(b)

Figure 5. SEM image of r-PP/PE blends moulded at (a) $180{ }^{\circ} \mathrm{C}$, (b) $200{ }^{\circ} \mathrm{C}$.

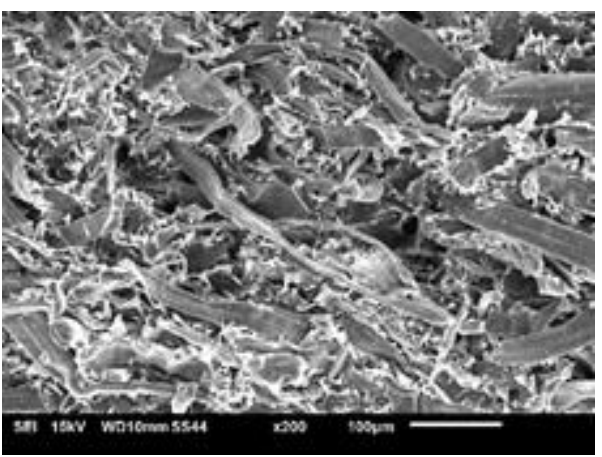

(a)

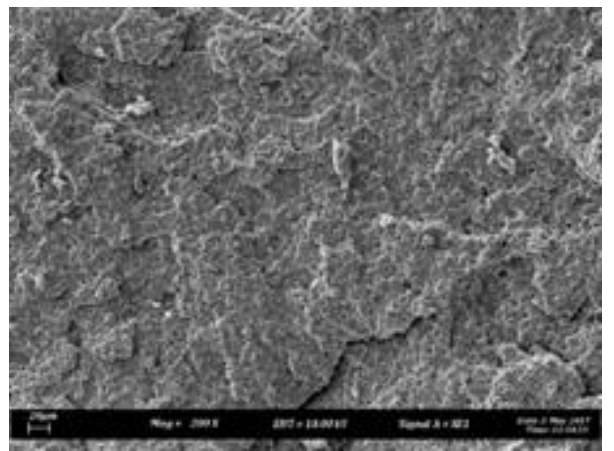

(b)

Figure 6. SEM image of tensile fracture surface blends moulded at $190{ }^{\circ} \mathrm{C}$ for (a) $\mathrm{r}$ PP/PE, (b) v-PP/PE.

\section{CONCLUSIONS}

In this work, the effect of temperature on the tensile properties of r-PP/PE and v-PP/PE is presented. For $\mathrm{r}-\mathrm{PP} / \mathrm{PE}$, the tensile strength and modulus were at the highest when the moulding temperature used was $180{ }^{\circ} \mathrm{C}$. The high temperature used showed the tensile strain increment. Meanwhile, the tensile strength of v-PP/PE can be obtained when the moulding temperature used was at $180{ }^{\circ} \mathrm{C}$. At $180{ }^{\circ} \mathrm{C}$, the tensile strength difference between $\mathrm{r}-\mathrm{PP} / \mathrm{PE}$ and $\mathrm{v}-\mathrm{PP} / \mathrm{PE}$ was $57 \%$. However, there was only $2 \%$ difference in tensile modulus. The lower tensile properties of $\mathrm{r}$-PP/PE were caused by the morphological characteristics. Even though the tensile strength of r-PP/PE was lower than $\mathrm{v}$-PP/PE, the tensile modulus was still comparable. In addition, the tensile properties of r-PP/PE could be improved through the addition of fibre and the reinforcement will be done in future work. The results from this paper may be useful in structural applications that require low tensile strength. 


\section{ACKNOWLEDGEMENTS}

This work was financially supported by the Universiti Teknikal Malaysia Melaka (PJP/2015/FKM(3A)/S01409). The authors thank the ZFH Industries Sdn Bhd on the raw materials, and Centre of Advanced Manufacturing (AMC) and Centre of Advanced Research on Energy (CARe) for use of their facilities.

\section{REFERENCES}

[1] Bertin S, Robin J-J. Study and characterization of virgin and recycled LDPE/PP blends. European Polymer Journal. 2002;38:2255-64.

[2] Strapasson R, Amico S, Pereira M, Sydenstricker T. Tensile and impact behavior of polypropylene/low density polyethylene blends. Polymer Testing. 2005;24:468-73.

[3] Jereme IA, Siwar C, Alam MM. Waste Recycling in Malaysia: Transition from Developing to Developed Country. Indian Journal of Education and Information Management. 2015;4:1-14.

[4] Espinosa-Valdemar RM, Turpin-Marion S, Delfín-Alcalá I, Vázquez-Morillas A. Disposable diapers biodegradation by the fungus Pleurotus ostreatus. Waste Management. 2011;31:1683-8.

[5] Colón J, Ruggieri L, Sánchez A, González A, Puig I. Possibilities of composting disposable diapers with municipal solid wastes. Waste Management \&and Research. 2011;29:249-59.

[6] Weisbrod AV, Van Hoof G. LCA-measured environmental improvements in Pampers ${ }^{\circledR}$ diapers. The International Journal of Life Cycle Assessment. 2012;17:145-53.

[7] ASTM S. D638: Standard test method for tensile properties of plastics. West Conshohocken (PA): ASTM International. 2010.

[8] Brinson HF, Brinson LC. Characteristics, applications and properties of polymers. Polymer Engineering Science and Viscoelasticity: Springer; 2015. p. 57-100.

[9] Dell'Erba R, Groeninckx G, Maglio G, Malinconico M, Migliozzi A. Immiscible polymer blends of semicrystalline biocompatible components: thermal properties and phase morphology analysis of PLLA/PCL blends. Polymer. 2001;42:783140.

[10] Madi N. Thermal and mechanical properties of injection molded recycled high density polyethylene blends with virgin isotactic polypropylene. Materials \& Design. 2013;46:435-41.

[11] Hubo S, Delva L, Van Damme N, Ragaert K. Blending of recycled mixed polyolefins with recycled polypropylene: effect on physical and mechanical properties. AIP Conference Proceedings: AIP Publishing; 2016. p. 140006. 